\title{
Overshadowing in the spatial domain
}

\author{
J. SÁNCHEZ-MORENO, T. RODRIGO, and V. D. CHAMIZO \\ University of Barcelona, Barcelona, Spain \\ and \\ N. J. MACKINTOSH \\ University of Cambridge, Cambridge, England
}

\begin{abstract}
In Experiments 1 and 2, rats were trained in a Morris water maze to locate a hidden platform, the location of which in the circular pool was defined by four visual landmarks (A, B, C, and D), spaced at equal intervals around the edge of the pool. Control animals were trained with these four visual landmarks only. But for animals in the overshadowing groups, an auditory component, X, was added to Landmark D. Test trials, given at the end of training, consisted of placing the rat in the pool with no platform present and recording the time rats spent in the platform quadrant. In Experiment 1, the overshadowing group spent less time in the platform quadrant than controls when tested with $\mathrm{D}$, but the two groups performed equally well on test trials that did not use D. We conclude that the auditory Component X overshadowed the visual Landmark D. In Experiment 2, we obtained evidence of reciprocal overshadowing, of D by X and of X by D. The results of Experiment 3 suggested that an appeal to generalization decrement might not be sufficient to explain these overshadowing effects.
\end{abstract}

According to O'Keefe and Nadel (1978), true spatial or locale learning involves animals in the construction of a cognitive map of their environment, in which they locate their own position and that of any places of interest. This map is regularly and rapidly updated to incorporate new information as it becomes available, but the processes whereby the map is initially built up and then, as necessary, updated, are said to be sharply distinguished from those underlying simple Pavlovian or operant conditioning. Pavlovian conditioning might result in the formation of an association between a particular cue, object, or landmark and the availability of food, and result in an animal learning to approach this landmark; in O'Keefe's and Nadel's terminology, however, this would be guidance, not true locale learning.

That there is some distinction between the two is suggested by a variety of experiments employing both mazes and Morris's (1981) swimming pool. In the latter case, guidance learning is implied by rats' ability to swim straight toward a visible platform, wherever it is located in the pool. But they can also learn to swim straight toward an invisible platform, provided that it stays in one fixed location, and provided also that there are fixed landmarks outside the pool that can be used to define that location. The distinction between guidance and locale learning here is implied by the effects of hippocampal lesions on rats' ability

\footnotetext{
This research was supported by grants from the U.K. Biotechnology and Biological Sciences Research Council to N.J.M., and from the Spanish Ministerio de Educación y Ciencia (DGICYT PB97-0965) to V.D.C. The authors thank Antoni Cosculluela for statistical advice. Correspondence should be addressed to either T. Rodrigo or V. D. Chamizo, Universitat de Barcelona, Laboratori de Psicologia Animal i Estabulari, Passeig de la Vall d'Hebron, 171, 08035-Barcelona, Spain (e-mail: vdchamizo@psi.ub.es).
}

to learn the new location of an invisible, but not a visible, platform (Morris, Garrud, Rawlins, \& O'Keefe, 1982; Sutherland, Whishaw, \& Kolb, 1982).

Morris (1981) suggested that if spatial or locale learning differed from Pavlovian or instrumental conditioning, it might not obey the same laws of association, and phenomena such as blocking or overshadowing, routinely observed in standard Pavlovian or instrumental experiments (and equally readily seen in other situations used to study associative learning; see Shanks, 1995), might not be observed in rats learning to locate a hidden platform in a swimming pool. In experiments on blocking, conditioning to one component, $\mathrm{B}$, of a compound cue, $\mathrm{AB}$, is blocked or prevented by prior conditioning to the other component, A. But if, as O'Keefe and Nadel (1978) seemed to suggest, cognitive maps are regularly updated to incorporate new information, animals trained to find a hidden platform in the presence of one set of landmarks (A) should incorporate a new landmark $(\mathrm{B})$ into their map, and also use it to locate the platform. In two experiments, however, Rodrigo, Chamizo, McLaren, and Mackintosh (1997) found significant evidence of blocking of one landmark by others in the swimming pool (see also Biegler \& Morris, 1999; and Roberts \& Pearce, 1999).

In the experiments reported here, we asked whether it would also be possible to find evidence of overshadowing between landmarks. In an overshadowing experiment, animals conditioned to a compound cue, $\mathrm{AB}$, show less conditioning to either of its two components, $\mathrm{A}$ or B, than animals conditioned to either A or B alone. Spetch (1995) has provided evidence of just such an overshadowing effect in spatial learning. She trained pigeons to peck at an invisible target on a screen, whose location was defined by several adjacent landmarks on the screen. She found 
that the control over pecking acquired by a landmark a given distance from the target was reduced by the presence of another closer to the target. This seems nice evidence of overshadowing by relative spatial proximity, analogous to the effect of relative temporal proximity observed in Pavlovian experiments (e.g., Revusky, 1971). Would animals trained to find a submerged platform with the aid of a number of different landmarks also show evidence of overshadowing - for example, less control by one of those landmarks than animals trained with only one or two in the first place? In practice, this is probably not a sensible question to ask, since we already know that when trained to find a goal whose location is defined by reference to a number of landmarks, rats will use many, if not most, of them. Thus, Rodrigo et al. (1997) trained rats to find a hidden platform in a swimming pool with the help of four external landmarks; when tested with any three or, after sufficient training, any two of the landmarks, they performed just as accurately as with all four present, although a single landmark alone was insufficient to locate the platform. Similar results have been observed in maze experiments (O'Keefe \& Conway, 1978). It is clear, therefore, that rats trained with four landmarks spaced evenly around a pool will learn about all four. We could perhaps have compared performance with three landmarks after animals had been trained with either four or, say, eight landmarks (both sets including the three to be tested), but it seemed likely that if we used too many landmarks, some would inevitably be less salient or noticeable than others, or that generalization decrement from training to test would be greater for animals trained with eight than for those trained with four.

It seemed more probable that we might observe evidence of overshadowing if two or more landmarks were made redundant by being placed in the same location. Four or five landmarks spaced evenly around the circumference of a pool might all provide equally useful information for defining the location of the platform. But if two of them were placed in exactly the same position, they would provide redundant information. Our experiments were designed, therefore, to see whether two landmarks placed in the same location would overshadow one another.

\section{EXPERIMENT 1}

In each of the experiments reported here, we trained rats to use a set of external landmarks to locate a hidden platform in a swimming pool. As in Rodrigo et al.'s (1997) experiments, use of our designated landmarks, rather than static room cues, was ensured by rotating the landmarks, and the platform with them, between each trial. For control animals in Experiment 1, there were four landmarksA, B, C, and D-present on each training trial, arranged symmetrically around the circumference of the pool, with the platform between B and C, as shown in Figure 1. Animals in an overshadowing group were trained with an additional landmark, X, located at D. Landmark D itself was a three-dimensional visual object, and $\mathrm{X}$ was an auditory signal from inside D. We have shown elsewhere that audi-

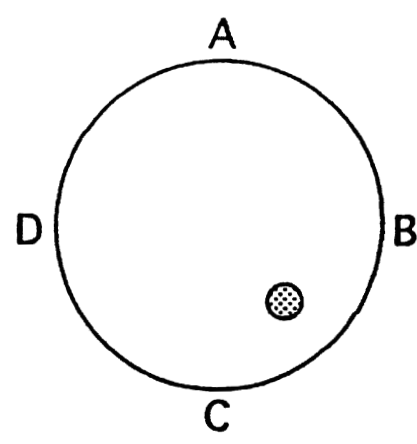

Figure 1. A schematic representation of the pool and four landmarks (A, B, C, and D), as well as the platform.

tory landmarks can be just as effective as visual landmarks in controlling rats' spatial learning (Sansa, Chamizo, \& Mackintosh, 1996). From Rodrigo et al.'s experiments, we also know that the four landmarks we used were equally effective: For example, there was no evidence there that Landmarks B and C, those closest to the platform, were more effective at controlling the rats' behavior than Landmarks A or D. It did not seen necessary, therefore, to counterbalance landmarks, nor to vary the landmark with which $\mathrm{X}$ was compounded. The question at issue was, in Experiment 1, whether the addition of $\mathrm{X}$ would detract from the control exercised by D and, in Experiment 2, whether D would also reciprocally overshadow X.

In order to ensure, as far as possible, that animals in the overshadowing and control groups had equal experience with Landmarks A-D (D included X for the overshadowing group) during initial training, this training was largely conducted by placing rats on the platform on each training trial, rather than allowing them to swim to the platform themselves (Rodrigo et al., 1997, employed the same procedure). Since Rodrigo et al. found that after such placement training rats are poor at finding the platform when fewer than three landmarks are available, test trials were always given with three landmarks - A, B, and C, or A, C, and $\mathrm{D}$ (no auditory cue present). We predicted that the overshadowing and control groups would perform equally well when tested with A, B, and C, but that the overshadowing group might perform less well than the control when tested with A, C, and D. The results of a preliminary experiment, virtually identical to the present Experiment 1 , revealed marginal evidence of such an overshadowing effect $(p=.08)$ - but only on a second series of test trials. One reason for this was that both groups performed rather poorly on their initial set of test trials. In Experiment 1, we attempted to improve initial test performance by giving more extended initial training.

\section{Method}

Animals. The animals were 26 Long Evans rats, 12 males and 14 females, approximately 5 months old at the beginning of the experiment; they had previously participated in a taste aversion experiment. They were divided into two groups, overshadowing and control, of 13 rats each, respectively, matched for sex and for latency to find the platform on pretraining trials. They were maintained on ad- 
lib food and water, in a colony room maintained on a 12:12-h light:dark cycle, and were tested within the first $4 \mathrm{~h}$ of the light cycle.

Apparatus. The apparatus was a circular swimming pool, made of plastic and fiberglass, modeled after that used by Morris (1981), and described in detail in Rodrigo et al. (1997). It measured $1.58 \mathrm{~m}$ in diameter and $0.65 \mathrm{~m}$ in depth, and was filled to a depth of $0.49 \mathrm{~m}$ with water rendered opaque by the addition of $1 \mathrm{cl} / 1$ of latex. The water temperature was maintained at $22 \pm 1{ }^{\circ} \mathrm{C}$. The pool was situated in the middle of a large room, mounted on a wooden platform $0.43 \mathrm{~m}$ above the floor, and was surrounded by black curtains reaching from ceiling to the base of the pool and forming a circular enclosure $2.4 \mathrm{~m}$ in diameter. Inside the black enclosure, around the curtains, and hanging from a false black ceiling, a number of objects were placed. These objects or landmarks defined the location of the platform, which was always situated between Landmarks B and C. In order to ensure that the rats used these landmarks, rather than any inadvertently remaining static room cues, to locate the platform, the landmarks and platform were rotated with respect to the room between each trial throughout the experiment. Each of four possible orientations $\left(0^{\circ}, 90^{\circ}, 180^{\circ}, 270^{\circ}\right)$ was used, in a random sequence, in each block of four trials. A closed-circuit video camera with a wide-angle lens was mounted $1.75 \mathrm{~m}$ above the center of the pool inside the false ceiling, and its picture was relayed to recording equipment in an adjacent room. A circular platform, $0.11 \mathrm{~m}$ in diameter and made of transparent Perspex, was mounted on a rod and base, and could be placed in one quadrant of the pool, $0.38 \mathrm{~m}$ from the side, with its top $1 \mathrm{~cm}$ below the surface of the water.

The four landmarks used were as follows: A: a 40-W light placed inside a white plastic inverted cone $11 \mathrm{~cm}$ high and $13 \mathrm{~cm}$ in diameter at the base; B: a 30-cm diameter plastic beach ball with alternate blue, white, yellow, white, orange, and white vertical segments; C: an intermittent $1-\mathrm{W}$ light flashing on and off at a frequency of 1 to $1.2 \mathrm{~Hz}$; D: a green plastic plant approximately $35 \mathrm{~cm}$ in diameter and $30 \mathrm{~cm}$ high. This landmark, D, could also include an auditory component, X (effectively, white noise), produced by a small radio, hidden among the leaves, with a nontuned broadcasting station switched on. When this was the case, we refer to this landmark as " $\mathrm{D}+\mathrm{X}$." The ambient sound level recorded at the center of the pool was $27-28 \mathrm{~dB}$. This was raised to $49-53 \mathrm{~dB}$ by the addition of X. The landmarks were suspended from the false ceiling, $35 \mathrm{~cm}$ above the surface of the water with the midline directly above the wall of the pool. Their location relative to the platform was as shown in Figure 1. The entire false ceiling, with these landmarks suspended, could be rotated from trial to trial, and the platform always rotated with them.

Procedure. There were four types of trials: pretraining, placement trials, escape training, and test trials. Pretraining consisted of placing the rat into the pool, without landmarks but with the platform present. The rat was given $180 \mathrm{sec}$ to find the platform, and once it had found it, it was allowed to stay on it for $30 \mathrm{sec}$. If it had not found the platform within $180 \mathrm{sec}$, it was picked up, placed on it, and left for $30 \mathrm{sec}$. Rats were given five such pretraining trials, at a rate of one per day. The platform was moved from one trial to the next, and the rat was placed in the pool in a different location on each trial (at one of the four points indicated by landmarks, A, B, C, and $\mathrm{D}$ in Figure 1).

After pretraining, training consisted of placement trials. These trials involved placing the rat directly onto the platform and leaving it there for $60 \mathrm{sec}$. Landmarks were always present. For the overshadowing group, these were $\mathrm{A}, \mathrm{B}, \mathrm{C}$, and $\mathrm{D}+\mathrm{X}$, whereas for the control group they were $\mathrm{A}, \mathrm{B}, \mathrm{C}$, and $\mathrm{D}$. The rats received 8 days of placement trials, eight trials per day (a total of 64 trials), with an average intertrial interval (ITI) of 7-8 min.

At the end of training, all rats received 1 day with four escape trials, and on each of the following 4 test days, four escape trials followed by one test trial. Escape trials involved placing the rat into the pool, with the landmarks and the platform present. The landmarks were as in training, $\mathrm{A}, \mathrm{B}, \mathrm{C}$, and $\mathrm{D}+\mathrm{X}$ for the overshadowing group, and $\mathrm{A}, \mathrm{B}, \mathrm{C}$, and $\mathrm{D}$ for the control animals. Animals were given $180 \mathrm{sec}$ to find the platform, and once they had found it, they were allowed to stay on it for $30 \mathrm{sec}$. These trials had an average ITI of 10-20 min. Rats were placed in the pool once each at A, B, C, and $\mathrm{D}$ on the four trials of each day. A test trial consisted of placing the rat in the pool, with landmarks present but without the platform, and leaving it there for $120 \mathrm{sec}$. For both groups, the first two test trials were with Landmarks A, C, and D; the third and fourth were with Landmarks A, B, and C. For purposes of recording the rat's behavior, on test trials the pool was divided into four quadrants-A-B, B$\mathrm{C}$ (the platform quadrant), $\mathrm{C}-\mathrm{D}$, and $\mathrm{D}-\mathrm{A}$ - and the amount of time the rat spent in each quadrant was recorded. On all test trials, each animal was placed in the pool from one specific starting position (A, $\mathrm{B}, \mathrm{C}$, or D), although rats in both groups were, as much as possible, placed equally in all four starting positions. A significance level of $p<.05$ was adopted for all statistical tests reported in this and subsequent experiments.

\section{Results and Discussion}

On the first block of four escape trials (the day after placement training), the mean latency to find the platform was $31.86 \mathrm{sec}$ in the overshadowing group, and $32.65 \mathrm{sec}$ in the control group. By Block 5 (immediately before the final test trial in the presence of $\mathrm{A}, \mathrm{B}$, and C), these latencies had declined to 16.90 and to $14.54 \mathrm{sec}$, respectively. An analysis of variance (ANOVA) revealed a significant effect of days $[F(4,96)=13.70]$, but no other significant effect $(F \mathrm{~s}<1.5)$.

The results of the test trials to $\mathrm{A}, \mathrm{C}$, and $\mathrm{D}$, and $\mathrm{A}, \mathrm{B}$, and $\mathrm{C}$ are shown in Figure 2. It is evident that the two groups did not perform differently on the first trial to A, $\mathrm{C}$, and $\mathrm{D}$, but they did on their second, while there was little or no difference between them on either trial to A, B, and C. An overall ANOVA, with groups, type of test, and trials as factors, revealed a significant difference between groups $[F(1,24)=5.85]$ and type of test $[F(1,24)=35.02]$, as well as a significant interaction between groups, type of test, and trials $[F(1,24)=4.60]$. No other effect or interaction was significant $\left(F_{\mathrm{S}}<2.0\right)$. The triple interaction between groups, type of test, and trials was evaluated further by analysis of the group $\times$ trials interaction separately for each type of test. The interaction was significant on the $\mathrm{A}, \mathrm{C}$, and D test $[F(1,24)=6.87]$, but not on the A, B, and $\mathrm{C}$ test. Analysis of simple effects revealed that the overshadowing group performed significantly worse than the control group on the second test trial in the presence of $\mathrm{A}$, $\mathrm{C}$, and $\mathrm{D}$, but not on any other trial.

The results of this experiment, taken together with those of the preliminary experiment described earlier, provide good evidence that an auditory component of a landmark can overshadow a visual component: Animals trained with Landmark D + X - that is, with both the visual and the auditory component - performed rather worse on tests that included $\mathrm{D}$ than did animals trained without $\mathrm{X}$, but equally well on test trials that did not include D as one of the landmarks. One puzzle is that this overshadowing effect was not evident at the outset of testing: Indeed, it was not significant in the preliminary experiment, either, until a second set of tests was given. This may have been a consequence of our use of a placement procedure for training: 


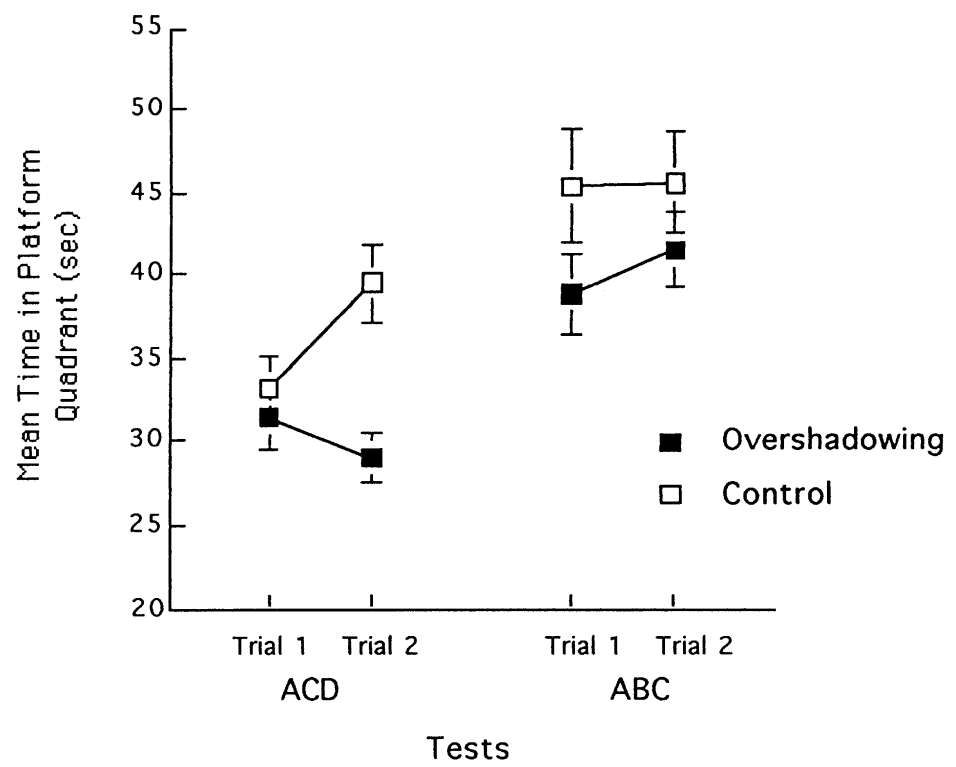

Figure 2. Experiment 1: Mean time $( \pm S E)$ spent in the platform quadrant (in seconds) on each test trial by overshadowing and control groups.

It is possible that rats need the experience of a number of escape training trials in order to reveal their knowledge of the location of the platform on a test trial. Similarly, Rodrigo et al. (1997) found that their blocking effect was not necessarily evident on a first test trial.

\section{EXPERIMENT 2}

Experiments on simple Pavlovian conditioning or operant discriminations have generally shown that, except where one cue is much more salient than another, overshadowing between two cues is reciprocal (e.g., Mackintosh, 1976; Miles \& Jenkins, 1973). And experiments on overshadowing in maze learning, between intramaze and extramaze cues, have also shown that such overshadowing effects are reciprocal (Chamizo, Sterio, \& Mackintosh, 1985; March, Chamizo, \& Mackintosh, 1992). Experiment 2 , therefore, was designed to see whether we could obtain similar evidence of reciprocal overshadowing between auditory and visual components of a landmark.

\section{Method}

Animals and Apparatus. The animals were 57 Long Evans rats, 26 males and 31 females, approximately 5 months old at the beginning of the experiment; 47 ( 22 males and 25 females) had previously participated in a taste aversion experiment; the remaining 10 were experimentally naive. Two females were eliminated by human error, leaving a total of 55 animals. They were maintained under the same conditions as in Experiment 1, and the apparatus, landmarks, and experimental room were also the same as those used in Experiment 1 . When the auditory cue, $X$, was presented alone (without $\mathrm{D}$ ), it was in exactly the same location as when it was presented with $\mathrm{D}$, but was made invisible by being hidden in a small piece of the black material used for the curtains. The rats were divided into three groups - overshadowing, control X, and control D, with 18,19 , and 18 animals, respectively, matched for sex, previous experience, and latency to find the platform on pretraining trials. The experiment was run in two identical replications, with 32 rats in the first replication and 23 in the second.

Procedure. The general procedure was exactly the same as in Experiment 1 ; the only exception was that all rats had three kinds of test trial instead of two. Rats in the overshadowing group were trained in the presence of $\mathrm{A}, \mathrm{B}, \mathrm{C}$, and $\mathrm{D}+\mathrm{X}$; those in the control $\mathrm{X}$ group, in the presence of A, B, C, and X; and animals in the control D group, in the presence of A, B, C, and D. Training was the same as in Experiment 1 , that is 8 days for a total of 64 placement trials. At the end of training, all animals received 1 day with four escape trials, and on each of the following 6 test days, four escape trials followed by one test trial. The landmarks on escape trials were the same for each group as in training. The procedure for escape training and test trials was the same as in Experiment 1. The first and second test trials were in the presence of A, C, and D; the third and fourth, with A, C, and $\mathrm{X}$; and the fifth and sixth, with $\mathrm{A}, \mathrm{B}$, and $\mathrm{C}$.

\section{Results and Discussion}

On the first block of four escape trials after the end of placement training, the mean latency to find the platform was $38.22 \mathrm{sec}$ in the overshadowing group, $27.73 \mathrm{sec}$ in the control X group, and $29.00 \mathrm{sec}$ in the control D group. By Block 7, these latencies had declined to 16.62, 11.49, and $17.99 \mathrm{sec}$, respectively. An ANOVA revealed a significant effect of days $[F(6,312)=10.76]$, but no difference between groups, and no interaction between groups and days (maximum $F=2.30$ ).

The results of the test trials to each of the three sets of landmarks are shown in Figure 3. On test trials to A, C, and $\mathrm{D}$, and to $\mathrm{A}, \mathrm{C}$, and $\mathrm{X}$, the overshadowing group performed less accurately than the control group initially trained with the relevant component of the landmark (con- 


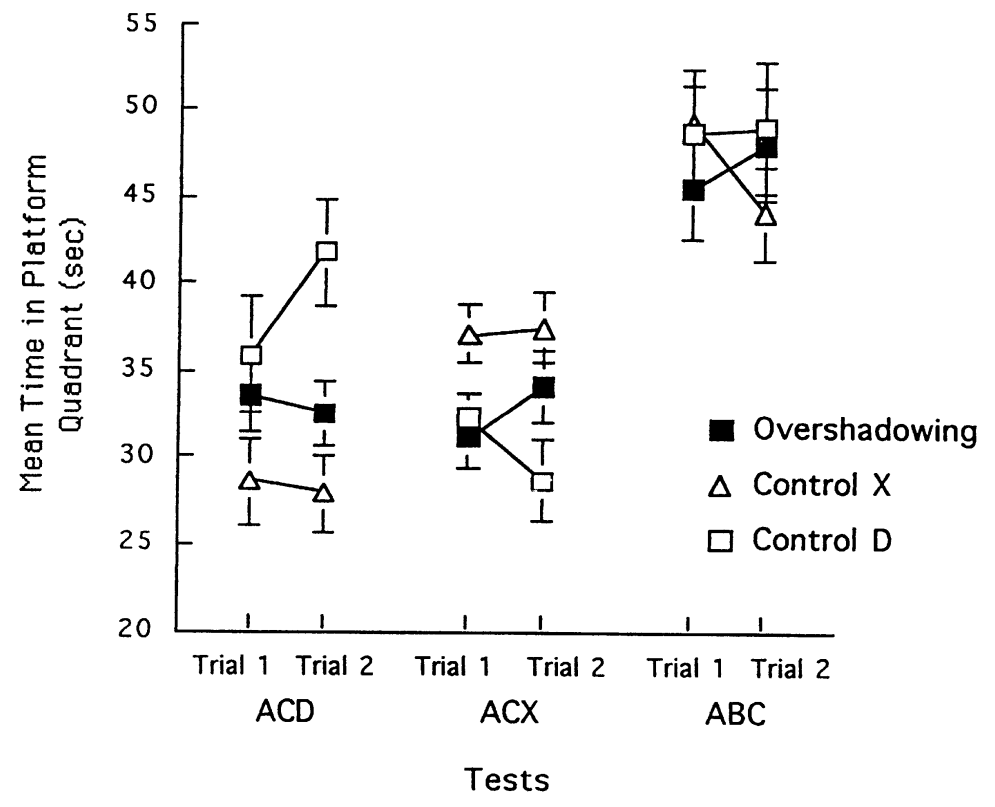

Figure 3. Experiment 2: Mean time $( \pm S E)$ spent in the platform quadrant (in seconds) on each of two test trials to each set of landmarks, for overshadowing, control D (trained with Landmark D), and control X (trained with Landmark X) groups.

trol $\mathrm{D}$ for the $\mathrm{A}, \mathrm{C}$, and $\mathrm{D}$ test, and control $\mathrm{X}$ for the $\mathrm{A}, \mathrm{C}$, and $\mathrm{X}$ test), but, unsurprisingly, more accurately than the control group that had never been trained with the component being tested. All three groups performed at a similar, high level of accuracy on the final test to A, B, and C.

Statistical analyses confirmed these impressions. An overall ANOVA, with groups, type of test, and trials as factors, revealed significant differences between the three types of test $[F(2,98)=48.91]$ and a significant interaction between groups and type of test $[F(4,98)=5.09]$. No other effects or interactions were significant (maximum $F=2.70$ ). Analysis of simple effects showed that there were differences between the performance of the three groups both on the $\mathrm{A}, \mathrm{C}$, and $\mathrm{D}$ and on the $\mathrm{A}, \mathrm{C}$, and $\mathrm{X}$ test $[F \mathrm{~s}(2,52)=5.55$ and 5.09 , respectively $]$, but not on the $\mathrm{A}$, $\mathrm{B}$, and $\mathrm{C}$ test $(F<1)$. The finding that the overshadowing and control groups performed equally well when tested with $\mathrm{A}, \mathrm{B}$, and $\mathrm{C}$ confirms the results of Experiment 1. The question of interest is whether the overshadowing group performed less accurately than the appropriate control group when tested either on A, C, and D or on A, C, and X. An ANOVA of A, C, and D and A, C, and X tests revealed a significant interaction between groups and type of test $[F(2,52)=15.49]$, and also a significant interaction between groups, type of test, and trials $[F(2,52)=4.30]$. No other effects or interactions were significant $\left(F_{\mathbf{S}}<1\right)$. The triple interaction between groups, type of test, and trials was evaluated further by analysis of the groups by type of test interaction separately for each trial. On the first trial, the interaction was significant $[F(2,52)=6.24]$, and analysis of simple effects revealed that there were differ- ences between the performance of the three groups on the $\mathrm{A}, \mathrm{C}$, and $\mathrm{X}$ test $[F(2,52)=3.76]$, but not on the $\mathrm{A}, \mathrm{C}$, and $\mathrm{D}$ test $(F<2.0)$. Newman-Keuls tests revealed that both the overshadowing and control D groups performed significantly worse than the control X group in the presence of $\mathrm{A}, \mathrm{C}$, and $\mathrm{X}$. On the second test trial, the interaction was also significant $[F(2,52)=15.89]$. Analysis of simple effects revealed that there were differences between the performance of the three groups both on the A, C, and D and on the $\mathrm{A}, \mathrm{C}$, and $\mathrm{X}$ test $\left[F_{\mathrm{s}}(2,52)=8.47\right.$ and 4.17 , respectively]. Newman-Keuls tests revealed that both the overshadowing and control $\mathrm{X}$ groups performed significantly worse than the control D group in the presence of A, C, and $\mathrm{D}$, and that the control $\mathrm{D}$ group performed significantly worse than the control X group in the presence of $\mathrm{A}, \mathrm{C}$, and $\mathrm{X}$.

The results of this experiment seem quite clear: Each of two components, one auditory, the other visual, of a "single" landmark was able to overshadow the other. Animals trained with both components present performed less accurately on test with either component than did animals initially trained with that component alone. But on the final test trials to A, B, and C, the performance of the overshadowing group was indistinguishable from that of the controls. It is true that here, as in Experiment 1, type of test trial was confounded with trial order. It might then be argued that the overshadowing group's performance was somehow disrupted on early test trials (those to A, C, and $\mathrm{D}$ or $\mathrm{A}, \mathrm{C}$, and $\mathrm{X})$, but eventually recovered so that they performed well on their final set of tests. It is not obvious why this should be so, or why the overshadowing 
group should have performed well on its third and fourth test trials in Experiment 1, but not until its fifth and sixth test trials in Experiment 2. Moreover, neither experiment yielded any evidence that the overshadowing group's performance significantly improved across the two test trials with the same set of landmarks.

\section{EXPERIMENT 3}

One possible explanation of overshadowing is to appeal to the concept of generalization decrement. Animals trained with a compound cue (here the Landmark D $+\mathrm{X}$ ) may perform less accurately when tested with either component (D or X) alone than animals initially trained with these components in isolation, because $\mathrm{D}$ or $\mathrm{X}$ alone are perceived as different from $\mathrm{D}+\mathrm{X}$, and responding established to one stimulus does not transfer perfectly to a different stimulus. We consider some problems with this explanation in the General Discussion. But an experimental test is also possible. If the difference between $\mathrm{D}+\mathrm{X}$ and $\mathrm{D}$ is sufficient to explain the disruption of an overshadowing group's performance, one might arguably expect a similar disruption in a group initially trained with $\mathrm{D}$ alone and then tested with D $+X$. Experiment 3 was designed to test this prediction. An experimental group was trained with $\mathrm{A}, \mathrm{B}, \mathrm{C}$, and $\mathrm{D}$ and then tested with $\mathrm{A}, \mathrm{C}$, and $\mathrm{D}+\mathrm{X}$. There were two control groups, one trained with A, B, C, and D and tested with $\mathrm{A}, \mathrm{C}$, and $\mathrm{D}$; the other trained with $\mathrm{A}, \mathrm{B}, \mathrm{C}$, and $\mathrm{D}+\mathrm{X}$ and tested, like the experimental group, with $\mathrm{A}, \mathrm{C}$, and $\mathrm{D}+\mathrm{X}$.

\section{Method}

Animals, Apparatus, and Procedure. The animals were 30 naive Hooded Lister rats, 15 males and 15 females, approximately 3 months old at the beginning of the experiment. One female was eliminated from the experiment by human error, leaving a total of 29 animals. They were divided into three groups-experimental, control-1, and control-2, of 10,9 , and 10 animals, respectively, matched for sex and for latency to find the platform on pretraining trials. They were maintained under the same conditions as in the previous experiments. The apparatus, landmarks, and experimental room, as well as the procedure for pretraining, training, and testing, were also exactly the same as in Experiments 1 and 2.

Rats in the experimental and control-1 groups were trained in the presence of $\mathrm{A}, \mathrm{B}, \mathrm{C}$, and $\mathrm{D}$, and animals in the control-2 group were trained with $\mathrm{A}, \mathrm{B}, \mathrm{C}$, and $\mathrm{D}+\mathrm{X}$. All animals received two test trials on consecutive days. Test trials were in the presence of $\mathrm{A}, \mathrm{C}$, and D $+\mathrm{X}$ for the experimental and control-2 animals; and in the presence of $\mathrm{A}, \mathrm{C}$, and $\mathrm{D}$ for the control-1 rats.

\section{Results and Discussion}

On the first block of four escape trials after the end of placement training, the mean latency to find the platform was $39.28 \mathrm{sec}$ in the experimental group, $26.59 \mathrm{sec}$ in control-1, and $51.77 \mathrm{sec}$ in control-2. By Block 3, these latencies had declined to 22.22, 19.13, and $21.29 \mathrm{sec}$, respectively. An ANOVA revealed a significant effect of days $[F(2,52)=10.04]$, but neither groups nor the interaction between groups and days was significant $\left(F_{\mathrm{S}}<1.4\right)$.

The results of the two test trials are shown in Figure 4. Performance was relatively poor, and very variable, on the first test trial, but seemed to improve on the second. On neither day was there any evidence that the experimental

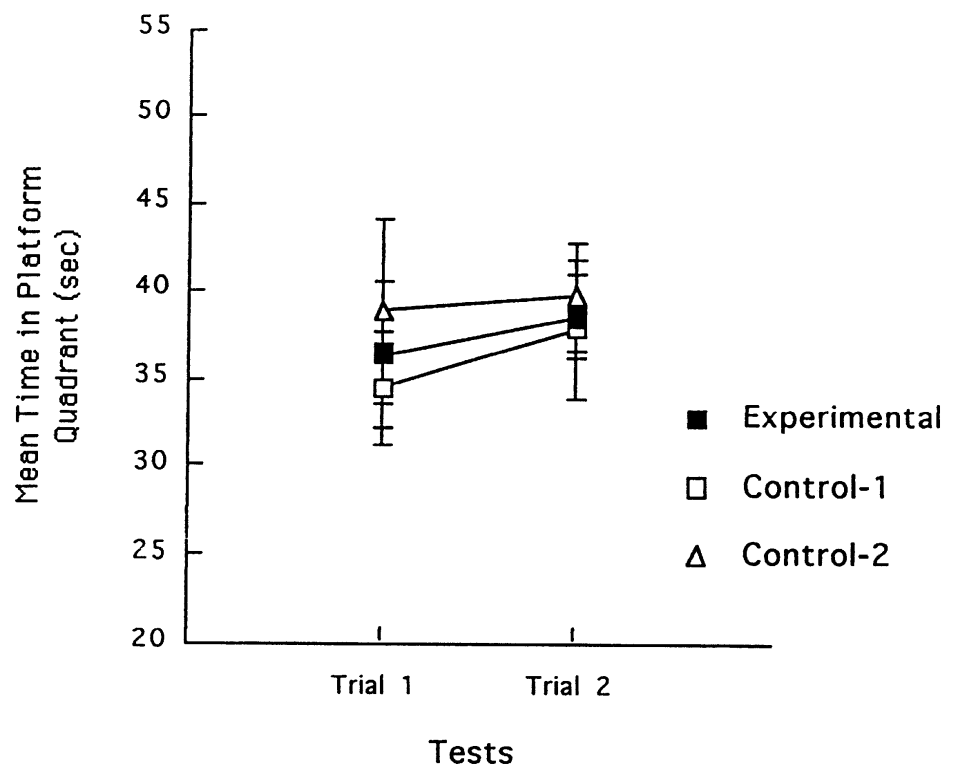

Figure 4. Experiment 3: Mean time $( \pm S E)$ spent in the platform quadrant on each test trial (in seconds). The experimental group was trained with $\mathrm{A}, \mathrm{B}, \mathrm{C}$, and $D$ and tested with $A, C$, and $D+X$. Control-1 was trained with $A, B, C$, and $D$ and tested with $A, C$, and $D$, while control-2 was trained with $A, B, C$, and $D$ $+X$ and tested with $A, C$, and $D+X$. 
group performed less accurately than the controls. An ANOVA with groups and trials as factors revealed no significant main effect or interaction $\left(F_{\mathrm{S}}<1\right)$. This absence of any reliable difference between the three groups would be uninteresting if they were all performing at chance. However, further analyses, which compared animals' performance against chance (i.e. $25 \%$ of the test trial being spent in the platform quadrant), revealed that performance did differ from chance both on Trial 1 and on Trial 2 $[t(28)=2.60$ and 4.95 , respectively $]$.

The results provide no evidence of significant generalization decrement. We acknowledge that we are reporting a null result - that the experimental group, tested with a different landmark $(D+X)$ from that which the group was trained (D), did not perform less accurately than control groups trained and tested with an unchanged landmark (whether D or D $+\mathrm{X}$ ). But the procedures employed here were exactly the same as those used in Experiments 1 and 2 , which did obtain significant overshadowing effects. The present results can thus be said to provide little support for an analysis of these overshadowing effects solely in terms of generalization decrement.

\section{GENERAL DISCUSSION}

The results of the present experiments establish that overshadowing occurs between landmarks in a standard spatial navigation task. They thus complement those of Rodrigo et al. (1997), who reported that prior training with one set of landmarks would block the acquisition of control by a newly added landmark in this situation.

Given that rats trained with four landmarks equally spaced around the circumference of the pool make equal use of all four landmarks to locate the platform (Rodrigo et al., 1997), it seems probable that the overshadowing effect observed here between $\mathrm{D}$ and $\mathrm{X}$ occurred because both landmarks were in exactly the same position, and in that sense truly redundant. If the platform was defined as being, inter alia, southeast of $\mathrm{D}$, no additional information is provided by saying that it is also southeast of $\mathrm{X}$ (or vice versa). If this is correct, our results bear a certain resemblance to those of Blaisdell, Denniston, and Miller (1998), who found greater overshadowing in Pavlovian conditioning between two cues that bore exactly the same temporal relation to the delivery of the unconditioned stimulus (US) than between two cues providing slightly different temporal information about the delivery of the US.

Both blocking and overshadowing effects are predicted by most current theories of associative learning: Indeed, their occurrence in a novel preparation is often thought to indicate that we are dealing with a standard associative paradigm. But both blocking and overshadowing are susceptible to alternative interpretations. If rats do not learn to use a newly added landmark to find a submerged platform whose location is already identified by other, previously trained landmarks, this apparent blocking effect could perhaps be explained by suggesting that the rats simply did not look toward the position of the new landmark and thus failed to incorporate it into their map. Although Rodrigo et al. (1997) presented evidence that argues against this interpretation of their results, it is difficult to rule it out categorically (but see Biegler \& Morris, 1999). It is not, however, a very plausible explanation of the present results. Because D and X were in the same location, and one of them was auditory, it does not make sense to say that the presence of one prevented animals from looking toward, or registering, the other.

Apparent overshadowing effects can also be interpreted in a number of other ways. One uninteresting possibility, noted by Wagner (1969), is that since an overshadowing group will be trained on a discrimination with more relevant cues than a control group, it may learn their discrimination more rapidly. In an instrumental paradigm, the animals will thus make fewer errors during the course of initial discrimination training, and if learning occurs particularly on trials when an animal makes an error, an overshadowing group may have less opportunity to learn about the target cue than would a control group. We controlled against this possibility by providing virtually all initial training by placement trials. It is further ruled out by the finding that overshadowing and control groups did not differ in their latency to find the platform on escape trials given at the end of placement training. By contrast, this seems a potential problem in interpreting the overshadowing effect reported by Spetch (1995). Although she ensured that her pigeons received equal amounts of training with both her overshadowed and her non-overshadowed cues, the overshadowed cue was embedded in an easier discrimination on which the birds made fewer (albeit not significantly fewer) errors.

A second possibility is that overshadowing can be explained simply by appeal to generalization decrement. It is never easy to rule out this possibility in experiments on overshadowing: Indeed, one contemporary analysis seeks to explain overshadowing entirely in these terms (Pearce, 1987, 1994). However, the present results do make it difficult to appeal solely to generalization decrement for their explanation. The first point to note is that in Experiments 1 and 2, all test trials for all groups would have allowed some generalization decrement to occur: The landmarks present on the $\mathrm{A}, \mathrm{B}$, and $\mathrm{C}$ tests, like those present on all others, were only a subset of those present in training. Indeed, A, B, and C constituted a smaller subset of the training landmarks for the overshadowing than for the control groups: In the former case, a double landmark $\mathrm{D}+\mathrm{X}$ had been removed, whereas in the latter only a single landmark. One might have supposed that $\mathrm{D}+\mathrm{X}$ would have been more salient than D or X alone, and therefore that its removal should have been more disruptive. But in neither experiment did the overshadowing group perform less accurately than the controls on tests to A, B, and C. Whether or not performance was as good as it would have been if animals had been tested with all the landmarks used in training, the results are consistent with those of 
other studies (see introduction) in suggesting that animals use most available landmarks when learning a spatial task, and thus that their encoding of spatial location is sufficiently redundant to survive the removal of any particular landmark.

The results of Experiment 3 provide suggestive further evidence against any simple appeal to generalization decrement. According to such an analysis, animals trained with $\mathrm{D}+\mathrm{X}$ performed poorly when tested with one component of this double landmark without the other, because D $+\mathrm{X}$ is a different (configural) stimulus from $\mathrm{D}$ or $\mathrm{X}$ alone. It seems plausible to argue, then, that animals trained with $D$ (without $\mathrm{X}$ ) should perform equally poorly when tested with D + X; according to Pearce (1994), for example, generalization decrement from $\mathrm{D}+\mathrm{X}$ to $\mathrm{D}$ should be exactly the same as generalization decrement from $\mathrm{D}$ to $\mathrm{D}+\mathrm{X}$. But in Experiment 3, such animals performed just as well as those trained and tested either with $\mathrm{D}+\mathrm{X}$ or with $\mathrm{D}$ on its own. Although this is only a null result, and although it may be difficult to rule out an analysis in terms of generalization decrement if that analysis has sufficiently imprecise rules for generalization, the results of all our experiments taken together suggest that the change from training to testing is probably not sufficient to explain the overshadowing effects observed here. We conclude that redundant landmarks may overshadow one another in a spatial task just as redundant cues overshadow one another in experiments on Pavlovian or instrumental conditioning.

\section{REFERENCES}

Biegler, R., \& Morris, R. G. M. (1999). Blocking in the spatial domain with arrays of discrete landmarks. Journal of Experimental Psychology: Animal Behavioral Processes, 25, 334-351.

Blaisdell, A. P., Denniston, J. C., \& Miller, R. R. (1998). Temporal encoding as a determinant of overshadowing. Journal of Experimental Psychology: Animal Behavior Processes, 24, 72-83.

Chamizo, V. D., Sterio, D., \& Mackintosh, N. J. (1985). Blocking and overshadowing between intra-maze and extra-maze cues: A test of the independence of locale and guidance learning. Quarterly Journal of Experimental Psychology, 37B, 235-253.

MacKINTOSH, N. J. (1976). Overshadowing and stimulus intensity. Animal Learning \& Behavior, 4, 186-192.
March, J., Chamizo, V. D., \& Mackintosh, N. J. (1992). Reciprocal overshadowing between intra-maze and extra-maze cues. Quarterly Journal of Experimental Psychology, 45B, 49-63.

Miles, C. G., \& JenKins, H. M. (1973). Overshadowing in operant conditioning as a function of discriminability. Learning \& Motivation, 4, $11-27$.

Morris, R. G. M. (1981). Spatial localization does not require the presence of local cues. Learning \& Motivation, 12, 239-260.

Morris, R. G. M., Garrud, P., Rawlins, J. N. P., \& O'Keefe, J. (1982). Place navigation impaired in rats with hippocampal lesions. Nature, 297, 681-683.

O'Keefe, J., \& Conway, D. H. (1978). Hippocampus place units in the freely moving rat: Why they fire where they fire. Experimental Brain Research, 31, 573-590.

O'KeEFe, J., \& NADEL, L. (1978). The hippocampus as a cognitive map. Oxford: Oxford University Press, Clarendon Press.

Pearce, J. M. (1987). A model for stimulus generalization in Pavlovian conditioning. Psychological Review, 94, 61-73.

Pearce, J. M. (1994). Similarity and discrimination: A selective review and a connectionist model. Psychological Review, 101, 587-607.

REVUSKY, S. (1971). The role of interference in association over a delay. In W. K. Honig \& P. H. R. James (Eds.), Animal memory (pp. 155214). New York: Academic Press.

Roberts, A. D. L., \& Pearce, J. M. (1999). Blocking in the Morris swimming pool. Journal of Experimental Psychology: Animal Behavior Processes, 25, 225-235.

Rodrigo, T., Chamizo, V. D., McLaren, I. P. L., \& Mackintosh, N. J. (1997). Blocking in the spatial domain. Journal of Experimental Psychology: Animal Behavior Processes, 23, 110-118.

Sansa, J., Chamizo, V. D., \& Mackintosh, N. J. (1996). Aprendizaje perceptivo en discriminaciones espaciales [Perceptual learning in spatial discriminations]. Psicológica, 17, 279-295.

Shanks, D. R. (1995). Human associative learning. Cambridge: Cambridge University Press.

Spetch, M. L. (1995). Overshadowing in landmark learning: Touchscreen studies with pigeons and humans. Journal of Experimental Psychology: Animal Behavior Processes, 21, 166-181.

Sutherland, R. J., Whishaw, I. Q., \& Kolb, B. (1982). A behavioral analysis of spatial localization following electrolytic, kainate- or colchicine-induced damage to the hippocampal formation in the rat. Behavioural Brain Research, 7, 133-153.

WAGNER, A. R. (1969). Incidental stimuli and discrimination learning. In R. M. Gilbert and N. S. Sutherland (Eds.), Animal discrimination learning (pp. 83-111). London: Academic Press.

(Manuscript received June 7, 1999; revision accepted July 27, 1999.) 